\title{
The Chinese Herbal Decoction Danggui Buxue Tang Inhibits Angiogenesis in a Rat Model of Liver Fibrosis
}

\author{
Jing Lv, ${ }^{1}$ Zhimin Zhao, ${ }^{1}$ Yuan Chen, ${ }^{1}$ Qinglan Wang, ${ }^{1}$ Yanyan Tao, ${ }^{1}$ Li Yang, ${ }^{2}$ \\ Tai-Ping Fan, ${ }^{3}$ and Chenghai Liu ${ }^{1,4,5}$ \\ ${ }^{1}$ Institute of Liver Diseases, ShuGuang Hospital, Shanghai University of Traditional Chinese Medicine, Shanghai 201203, China \\ ${ }^{2}$ The MOE Key Laboratory for Standardization of Chinese Medicines and the SATCM Key Laboratory for New Resources and Quality \\ Evaluation of Chinese Medicines, Institute of Chinese Materia Medica, Shanghai University of Traditional Chinese Medicine, \\ Shanghai 201210, China \\ ${ }^{3}$ Angiogenesis \& Chinese Medicine Laboratory, Department of Pharmacology, University of Cambridge, Cambridge CB2 1PD, UK \\ ${ }^{4}$ E-Institute of TCM Internal Medicine, Shanghai Municipal Education Commission, Shanghai 201203, China \\ ${ }^{5}$ Shanghai Key Laboratory of Traditional Chinese Clinical Medicine, Shanghai 201203, China
}

Correspondence should be addressed to Tai-Ping Fan, tpf1000@cam.ac.uk and Chenghai Liu, chenghai_liu@yahoo.com.cn

Received 20 February 2012; Revised 13 May 2012; Accepted 14 May 2012

Academic Editor: Chang-Quan Ling

Copyright ( 2012 Jing Lv et al. This is an open access article distributed under the Creative Commons Attribution License, which permits unrestricted use, distribution, and reproduction in any medium, provided the original work is properly cited.

\begin{abstract}
In this study, we investigated the anti-angiogenic effect of the Chinese herbal decoction Danggui Buxue Tang (DBT; Radix Astragali and Radix Angelicae sinensis in 5:1 ratio) in a rat model of liver fibrosis, in order to elucidate its mechanisms of action against liver fibrosis. Liver fibrosis was induced with $\mathrm{CCl}_{4}$ and high-fat food for 6 weeks, and the rats were treated with oral doses of DBT (6 g raw herbs/kg/d) and N-Acetyl-L-cysteine (NAC; $0.1 \mathrm{~g} / \mathrm{kg} / \mathrm{d}$ ). The results showed that both DBT and NAC attenuated liver fibrosis and neo-angiogenesis. Furthermore, DBT and NAC improved SOD activity but decreased MDA content and 8-OH-dG in fibrotic livers, with DBT being more effective than NAC. DBT decreased the expression of VEGF, Ang1 and TGF- $\beta 1$ and their signaling mediators, whereas NAC had no effect on VEGF and VEGFR2 expression. Both DBT and NAC reduced HIF-1 $\alpha$ gene and protein expression in fibrotic livers, with DBT being more effective. These data clearly demonstrate that the anti-fibrotic properties of DBT are related to its ability to inhibit angiogenesis and its anti-angiogenic mechanisms are associated with improving oxidative stress, regulating the expression and signaling of angiogenic factors, and especially modulating HIF- $1 \alpha$ in fibrotic livers.
\end{abstract}

\section{Introduction}

Angiogenesis is a hypoxia-driven and growth factor-dependent process that leads to the formation of neovasculature from preexisting blood vessels. Experimental and clinical studies have unequivocally shown that pathological angiogenesis, irrespective of etiology, plays a key role in the fibrogenic progression of chronic liver diseases [1-3], and the inhibition of pathological angiogenesis in liver not only can stop liver cancer development, but also regress or reverse liver fibrosis $[4,5]$.

Danggui Buxue Tang (DBT), an ancient traditional Chinese herbal formula composed of Huangqi (Radix Astragali) and Danggui (Radix Angelica sinensis) with a weight ratio of
$5: 1$, has wide pharmacological actions, including regulation of immune functions and protection against liver injuries [6]. Although there are no reports concerning the effect of DBT on liver cirrhosis, several studies have reported antifibrotic effects for its components. For example, the combination of Astragali and Angelicae sinensis significantly inhibited the progression of renal fibrosis. This treatment led to a decrease in histologic damage, type III and IV collagen expression, fibronectin, and laminin in a rat model of chronic puromycin-induced nephrosis [7]. Astragali significantly attenuated liver tissue collagen and hydroxyproline (Hyp) content in a rat model of liver fibrosis induced by albumin immune complex [8]. In a rat model of pulmonary fibrosis induced by intratracheal instillation of bleomycin, 
TABle 1: Antibodies used in the study.

\begin{tabular}{|c|c|c|c|c|}
\hline Antibody & Isotype & Suppliers & Cat. no. & Dilution \\
\hline Collagen type I & Mouse IgG1 & Sigma & C2456 & $1: 400$ \\
\hline$\alpha$-SMA & Rabbit polyclonal IgG & Abcam & ab5694 & $1: 400$ \\
\hline vWF & Rabbit polyclonal IgG & Abcam & ab6994 & $1: 200$ \\
\hline PECAM-1 & Goat polyclonal IgG & Santa Cruz & sc-1506 & $1: 200$ \\
\hline HIF- $1 \alpha$ & Rabbit monoclonal IgG & EPIT MICS & \#2015-1 & $1: 200$ \\
\hline VEGF & Rabbit polyclonal IgG & Abcam & $\mathrm{ab} 46154$ & $1: 400$ \\
\hline VEGFR2 & Rabbit polyclonal IgG & Abcam & ab39638 & $1: 500$ \\
\hline Angiopoietin 1 & Rabbit polyclonal IgG & Abcam & ab95230 & $1: 200$ \\
\hline Tie-2 & Rabbit polyclonal IgG & Abcam & ab71712 & $1: 250$ \\
\hline TGF- $\beta 1$ & Mouse IgG1 & R\&D systems & MAB240 & $1: 500$ \\
\hline $\mathrm{TGF} \beta-\mathrm{R} 1$ & Rabbit polyclonal IgG & Cell signal technology & \#3712 & $1: 1000$ \\
\hline TGF $\beta$-R2 & Mouse $\operatorname{IgG}_{2 \mathrm{a}}$ & Santa Cruz & sc-17792 & $1: 200$ \\
\hline ERK & Mouse $\operatorname{IgG}_{2 \mathrm{~b}}$ & Santa Cruz & sc- 1647 & $1: 200$ \\
\hline p-ERK & Mouse $\operatorname{IgG}_{2 \mathrm{a}}$ & Santa Cruz & sc-7383 & $1: 200$ \\
\hline
\end{tabular}

Angelica sinensis ameliorated fibrosis by inhibiting thromboxane $\mathrm{B}_{2}$ level and transforming growth factor- $\beta 1$ (TGF$\beta 1$ ) expression [9].

Our previous study found that DBT was able to ameliorate liver fibrosis induced by carbon tetrachloride $\left(\mathrm{CCl}_{4}\right)$ in rats, with the best results seen with a 5:1 ratio of Radix Astragali and Radix Angelicae sinensis [10]. In a subsequent study, we showed that this protective effect of DBT was associated with the prevention of lipid peroxidation and the inhibition of matrix metalloproteinases 2/9 (MMP 2/9) activities in fibrotic livers [11].

In the present study, we observed the effects of DBT on angiogenesis in fibrotic livers, with the antioxidant $\mathrm{N}$ Acetyl-L-cysteine (NAC) as a positive control drug. To test the hypothesis that the antifibrotic properties of DBT are related to its ability to inhibit angiogenesis, we also analyzed its effects on oxidative stress injury, expression of VEGF, TGF- $\beta 1$, and Ang1, expression of VEGF-R2, TGF $\beta-R 1 / 2$ and Tie2 receptors, and ERK phosphorylation, in particular HIF$1 \alpha$ expression in the fibrotic liver. Collectively, our data demonstrate that the anti-angiogenic mechanisms of DBT in fibrotic livers are associated with improving oxidative stress, regulating angiogenic factors expression and signaling, and especially modulating the gene and protein expression of HIF- $1 \alpha$.

\section{Materials and Methods}

2.1. Reagents. $\mathrm{CCl}_{4}$, olive oil and N-Acetyl-L-cysteine (NAC) were purchased from Shanghai National Chemicals Co., Ltd. (Shanghai, China). Bovine serum albumin (BSA) was purchased from Sino-American Biotechnology Co. (Henan, China). The primary antibodies used in this study are listed in Table 1. Nitrocellulose membrane (Hybond-C, optimized for protein transfer) was purchased from Amersham Biosciences UK, Ltd. (Buckinghamshire, UK). Horseradish peroxidase-labeled goat anti-mouse antibody and goat antirabbit antibody were obtained from Santa Cruz Biotechnology (California, USA). Cy3-labeled goat anti-rabbit IgG $(\mathrm{H}+\mathrm{L})$, Cy3-labeled donkey anti-goat IgG $(\mathrm{H}+\mathrm{L})$, and 2-(4-Amidinophenyl)-6-indolecarbamidine dihydrochloride (DAPI) were provided by the Beyotime Institute of Biotechnology (Jiangsu, China). The BCA Protein Assay Kit and the SuperSignal West Pico Chemiluminescent Substrate (ECL) were obtained from Pierce Chemical Company (Rockford, USA). TRIzol was obtained from Invitrogen (California, USA). The First-Strand cDNA Synthesis Kit (K1622) was purchased from Fermentas (St. Leon-Roth, Germany). The SYBR Green Real Time PCR Kit (DRR041A) was from TakaRa Biotechnology Co., Ltd (Dalian, China). Superoxide dismutase (SOD), malondialdehyde (MDA), and 8-hydroxydeoxyguanosine (8-OH-dG) were obtained from Nanjing Jiancheng Bioengineering Institute (Nanjing, China).

2.2. Preparation of Danggui Buxue Decoction. DBT consists of Radix Astragali and Radix Angelica sinensis in a 5:1 ratio. The herbs originated from Gansu province, China. Slices of the herbs were purchased from Shanghai Huayu Chinese Herbs Co., Ltd. The medicinal herbs were extracted twice. Radix Astragali (1000 g) and Radix Angelica sinensis (200 g) were first boiled together in $6 \mathrm{x}$ volume of water for $1 \mathrm{~h}$, and then the residue from first extraction was boiled in $8 \mathrm{x}$ volume of water for $1.5 \mathrm{~h}$. Finally, the filtered solutions were combined and concentrated into the resulting aqueous extracts containing $0.9 \mathrm{~g} / \mathrm{mL}$ raw herbs. The quantitative analyses of active compounds were verified by Professor Li. Yang (Table 2).

2.3. Animal Models of Liver Fibrosis and Drug Treatment. Fifty-four male Wistar rats (SCXK [Shanghai] 2007-005) were obtained from the Shanghai Laboratory Animal Center of the Chinese Academy of Sciences. All animal protocols were carried out in accordance with ethical guidelines, and animals had free access to chow and water throughout the 
TABLE 2: The amounts of six compounds in DBT.

\begin{tabular}{lc}
\hline Compound & $\begin{array}{c}\text { DBT (Radix Astragali: Radix } \\
\text { Angelica sinensis }=5: 1)\end{array}$ \\
\hline Astragaloside IV & $61.63 \pm 2.06$ \\
Calycosin & $2.29 \pm 0.08$ \\
Calycosin-7-O- $\beta$-D-glucoside & $2.20 \pm 0.03$ \\
Formononetin & $0.68 \pm 0.00$ \\
Formononetin-7-O- $\beta$-D- & $1.12 \pm 0.07$ \\
glucoside & $0.98 \pm 0.02$ \\
Ferulic acid &
\end{tabular}

Values are expressed in $10^{-2} \mathrm{mg} / \mathrm{g}$ of raw herbs and are in $\bar{X} \pm \mathrm{sd}, n=3$.

experiments. Liver fibrosis was induced by subcutaneous injection of $\mathrm{CCl}_{4}$ and the administration of food with a high lipid content and lower protein content [12]. Briefly, the rats received a single injection of $100 \% \mathrm{CCl}_{4}$ at $5 \mathrm{~mL} / \mathrm{kg}$ and then $3 \mathrm{~mL} / \mathrm{kg}$ of $40 \% \mathrm{CCl}_{4}$ dissolved in olive oil twice every week for 6 weeks. These rats were pair-fed with a high lipid and low protein diet containing $79.5 \%$ corn flour, $20 \%$ lard, and $0.5 \%$ cholesterol for the first 2 weeks, then with pure corn flour feeds for the following 4 weeks. Rats in the normal group $(n=8)$ did not receive $\mathrm{CCl}_{4}$ treatment and were fed a normal diet.

The model rats were randomly divided into three groups: model $(n=12)$, DBT $(n=12)$, and NAC $(n=12)$. The rats in the DBT group received intragastric administrations of DBT at $6 \mathrm{~g}$ (raw herbs) $/ \mathrm{kg} / \mathrm{d}$. Rats in the NAC group received intragastric administrations of NAC at $0.1 \mathrm{~g} / \mathrm{kg} / \mathrm{d}$. Both drug treatment duration is 6 weeks, which means from the beginning of intoxication to the end of experiment, and both dosages are equivalent to 10 times the clinical dosage for a $60 \mathrm{~kg}$ adult. Rats in the normal and model groups received the same volume $(10 \mathrm{~mL} / \mathrm{kg})$ of normal saline.

2.4. Pathological Examination. Liver specimens were preserved in $4 \%$ formaldehyde and dehydrated in a graded alcohol series. The specimens were then embedded in paraffin blocks, cut into $4 \mu \mathrm{m}$ thick sections and placed on glass slides. Sections were then stained with Sirius red.

2.5. Hepatic Hyp Content Examination. Hepatic Hyp content was measured with a modified version of the method developed by Jamall et al. [13]. Briefly, $100 \mathrm{mg}$ of liver samples were homogenized and hydrolyzed in $12 \mathrm{M} \mathrm{HCl}$ at $110^{\circ} \mathrm{C}$ for $18 \mathrm{~h}$. After filtration of the hydrolysate through filtration paper, chloramine $\mathrm{T}$ was added to a final concentration of $2.5 \mathrm{mM}$ for $10 \mathrm{~min}$ at room temperature. The mixture was then treated with $25 \%(\mathrm{w} / \mathrm{v}) \mathrm{p}$-dimethylaminobenzaldehyde and $27.3 \%(\mathrm{v} / \mathrm{v})$ perchloric acid in isopropanol (Ehrlich's reagent solution) and incubated at $50^{\circ} \mathrm{C}$ for $90 \mathrm{~min}$. After cooling to room temperature, the samples were examined at $558 \mathrm{~nm}$ against a reagent blank that contained the complete system without tissue. The concentration of Hyp in each sample was determined from a standard curve, which was generated from a serial of known quantities of Hyp from
0.2 to $1.6 \mu$ g Hyp (Peptide Co. Japan). The Hyp content is expressed as $\mu \mathrm{g} / \mathrm{g}$ of liver wet weight.

2.6. Immunohistochemistry. $4 \mu \mathrm{m}$ thick sections were used for immunohistochemical examinations. After deparaffinization and dehydration, microwave antigen retrieval was performed for $5 \mathrm{~min}$ prior to peroxidase quenching with 3\% $\mathrm{H}_{2} \mathrm{O}_{2}$ in PBS for $15 \mathrm{~min}$. Consequently, the sections were preblocked with $5 \%$ bovine serum albumin for $30 \mathrm{~min}$. Slides were incubated at $4^{\circ} \mathrm{C}$ with primary antibodies (Table 1) at $37^{\circ} \mathrm{C}$ for $70 \mathrm{~min}$ and then with biotinylated secondary antibodies for $45 \mathrm{~min}$. They were then developed with DAB for 3 min and finally counterstained with hematoxylin. For the negative controls, the primary antibody was replaced with PBS.

2.7. Immunofluorescence. Frozen liver tissue slices $(7 \mu \mathrm{m}$ thick) were fixed with cold acetone for $10 \mathrm{~min}$ and dried in air for $30 \mathrm{~min}$. The slices were rinsed with PBS for $3 \times 5 \mathrm{~min}$ and blocked with $0.2 \%$ BSA for $1 \mathrm{~h}$ at $37^{\circ} \mathrm{C}$ before being incubated with the specific primary antibodies (Table 1 ). To visualize the primary antibodies, the slices were stained with cy3-labeled secondary antibodies for $1 \mathrm{~h}$ at $37^{\circ} \mathrm{C}$. After nuclear staining with DAPI $(1: 1000$; Beyotime) for $1 \mathrm{~min}$, the slices were observed using immunofluorescence microscopy (OLYMPUS ZX70). Negative control staining was performed using PBS instead of the primary antibody. Microvessel density was determined in the tissue as the mean number of labeled vessel sections in 5 successive highmagnification fields $(\times 400)$ with IPP software. The results are expressed as the means $\pm \mathrm{SD}$.

2.8. Western Blotting Analysis. Liver tissues were homogenized in RIPA lysis buffer $(150 \mathrm{mM} \mathrm{NaCl}, 1 \%$ Nonidet P-40, 0.1\% SDS, $50 \mathrm{mM}$ Tris- $\mathrm{HCl} \mathrm{pH}$ 7.4, $1 \mathrm{mM}$ EDTA, $1 \mathrm{mM}$ PMSF, and $1 \times$ Roche complete mini protease inhibitor cocktail). The supernatants were collected by centrifugation at $10,000 \times \mathrm{g}$ at $4^{\circ} \mathrm{C}$ for $15 \mathrm{~min}$. Protein concentration was determined using a BCA Protein Assay Kit. Equal amounts of protein were separated by $10 \%$ SDS gel electrophoresis (SDS-PAGE) under denaturing and nonreducing conditions and then transferred to a nitrocellulose membrane. The membrane was blocked with 5\% nonfat milk in TBST at room temperature for $1 \mathrm{~h}$ and then incubated with primary antibody (Table 1) at $4^{\circ} \mathrm{C}$ overnight. After washing in TBST, the blots were incubated with a horseradish-coupled secondary antibody. The signals were visualized using the enhancement system (ECL).

2.9. Fluorescence Western Blot. The fluorescence western blot protocol is the same as the general western blot protocol until the membrane transformation step. The membranes were blocked in blocking buffer (Odyssey, LI-COR, USA) for $1 \mathrm{~h}$ at room temperature followed by incubation with primary antibodies (Table 1 ) at $4^{\circ} \mathrm{C}$ overnight. After washing in PBS, the blots were incubated with the second antibody (Donkey anti-Rabbit IRDye 680 antibody; 1:10000; Odyssey) for $1 \mathrm{~h}$ at room temperature. After washing, the densities of 
TABLE 3: Primers used for real-time PCR.

\begin{tabular}{lcc}
\hline Gene & Primer sequences & Gene bank accession no. \\
\hline HIF1 $\alpha$ & $5^{\prime}$-CCAGATTCAAGATCAGCCAGCA-3' & NM_024359 \\
& $5^{\prime}$-GCTGTCCACATCAAAGCAGTACTCA-3' & \\
$\beta$-actin & $5^{\prime}$-TGA CGA GGC CCA GAG CAA GA-3' & DQ237887 \\
& $5^{\prime}$-ATG GGC ACA GTG TGG GTG AC-3' & 331 \\
\hline
\end{tabular}

immunoreactive bands were quantified and corrected for GAPDH signal with Li-Cor Odyssey 2.1 software (LI-COR, USA).

2.10. RNA Extraction and Quantitative Real-Time PCR. Total RNA was isolated from the liver tissues with TRIzol according to the manufacturer's instructions. RNA purity was determined spectrophotometrically, and its integrity was verified by agarose gel electrophoresis. First-Strand cDNA was synthesized by reverse transcribing $4 \mu \mathrm{g}$ of total RNA in a final reaction volume of $20 \mu \mathrm{L}$ using a First-Strand cDNA Synthesis Kit according to the manufacturer's instructions. Primer oligonucleotide sequences specific for real-time PCR are shown in Table 3 and were designed and synthesized by Sangon Biotech Inc. (Shanghai, China). The PCR mixtures contained $1 \mu \mathrm{L}$ cDNA, $10 \mu \mathrm{L}$ SYBR Premix Ex Tq $2 \mathrm{X}$, and $0.25 \mu \mathrm{mol} / \mathrm{L}$ forward and reverse primers in a final volume of $20 \mu \mathrm{L}$. Triplicate reactions were performed with a Rcorbett 6.0 system (Rotor-Gene 3000), starting with a polymerase activation step for $10 \mathrm{~s}$ at $95^{\circ} \mathrm{C}$, followed by 40 cycles of $5 \mathrm{~s}$ at $95^{\circ} \mathrm{C}$ and $20 \mathrm{~s}$ at $60^{\circ} \mathrm{C}$. Fluorescence data were acquired after each cycle. The absence of primer dimers and unspecific products was verified after every run by melting curve analysis $\left(72\right.$ to $95^{\circ} \mathrm{C}$ ) and agarose gel electrophoresis.

2.11. Hepatic Oxidative Injury Examination. SOD, MDA and $8-\mathrm{OH}-\mathrm{dG}$ levels in the liver homogenates were quantified using commercially available kits according to the manufacturer's instructions (Nanjing Jiancheng Co. Ltd.). Results were normalized to the total amount of protein measured by bicinchoninic acid (BCA).

2.12. Statistical Analysis. Statistical tests were performed using SPSS software version 12.0. Differences between two groups were analyzed by the SNK- $q$ ' test. $P$ values lower than 0.05 were considered statistically significant.

\section{Results}

3.1. DBT and NAC Ameliorated Liver Fibrosis Induced by $C C l_{4}$. The model rats had increased collagen deposition in the liver, which formed fibrous septa and cirrhotic nodules or pseudolobules. The doses of DBT and NAC used in this study were calculated according to their usage in patients with liver cirrhosis. Figures 1(a) and 1(b) show that DBT- and NAC-treated rats had much less liver collagen accumulation compared to the model control. This was confirmed with Hyp content as a specific marker for collagen synthesis. Compared to normal rats, Hyp content was increased
TABLE 4: Effect of DBT on hepatic HIF- $1 \alpha$ mRNA expression in $\mathrm{CCl}_{4}$-induced fibrosis in rats $(\bar{X} \pm \mathrm{sd})$.

\begin{tabular}{llc}
\hline Group & $n$ & HIF- $1 \alpha / \beta$-actin mRNA \\
\hline Normal & 3 & $0.98 \pm 0.03$ \\
Model & 3 & $3.32 \pm 0.46^{\# \#}$ \\
DBT & 3 & $0.49 \pm 0.04^{* * \wedge \wedge}$ \\
NAC & 3 & $0.86 \pm 0.05^{* *}$
\end{tabular}

$\#^{\#} P<0.01$ versus normal group, ${ }^{* *} P<0.01$ versus model group, ${ }^{\wedge \wedge} P<$ 0.01 versus $\mathrm{NAC}$ group.

significantly in model rats and significantly decreased by DBT and NAC treatment $(P<0.01$; Figure $1(\mathrm{c}))$.

3.2. Effect of DBT and NAC on Hepatic Stellate Cell (HSC) Activation. $\alpha$-SMA is a marker of HSC activation. We measured the expression of $\alpha$-SMA by immunohistochemical staining and western blot analysis. $\mathrm{CCl}_{4}$ treatment caused a significant increase in the expression of $\alpha$-SMA positive HSCs around damaged hepatocytes and fibrotic bands compared to the normal group. In DBT- and NACtreated animals, the number of $\alpha$-SMA-positive HSCs was significantly reduced. Western blot analysis revealed that the $\alpha$-SMA expression in model rats was almost 5 times higher than that in normal rats. Treatment with DBT and NAC resulted in significant reductions. In addition, there was a significant difference between the DBT and NAC group $(P<0.01$; Figures $2(\mathrm{a}), 2(\mathrm{~b})$ and $2(\mathrm{c}))$; DBT was more effective.

3.3. Effect of DBT and NAC on Tissue Angiogenesis. Immunofluorescence for von Willebrand factor (vWF) and platelet/endothelial cell adhesion molecule-1 (PECAM-1, also referred to as CD31) was performed to analyze microvessel growth. In normal livers, vWF is expressed in the great vessels of the portal tract and central veins but not along sinusoids, and CD31 is rarely expressed. In $\mathrm{CCl}_{4^{-}}$ treated livers, we observed vWF/CD31-positive microvessels located in fibrotic areas surrounding larger vessels, as well as in emerging fibrotic septa. As illustrated in Figure 3(c), DBT and NAC reduced the number of vWF/CD31-positive microvessels, which were also concentrated in fibrotic areas. DBT was more effective than NAC in reducing vWF expression $(P<0.01)$.

3.4. Effect of DBT and NAC on Hypoxia Inducible Factor (HIF)-1 $\alpha$. Real-time PCR analysis showed that the expression of HIF- $1 \alpha$ mRNA in the model livers was 3 times higher than in the normal group (Table 4). DBT and NAC 
TABLE 5: Effect of DBT and NAC on hepatic SOD activity and MDA and 8-OH-dG contents in $\mathrm{CCl}_{4}$-induced fibrosis $(\bar{X} \pm$ sd).

\begin{tabular}{lcccc}
\hline Group & $n$ & MDA $(\mu \mathrm{mol} / \mathrm{g})$ & SOD $(\mathrm{NU} / \mathrm{g})$ & $8-\mathrm{OHDG}(\mathrm{ng} / \mathrm{mL})$ \\
\hline Normal & 8 & $457.9 \pm 140.6$ & $42.9 \pm 8.7$ & $1.6 \pm 0.6$ \\
Model & 10 & $1054.5 \pm 255.0^{\# \#}$ & $24.7 \pm 4.1^{\# \#}$ & $2.8 \pm 0.8^{\# \#}$ \\
DBT & 12 & $642.8 \pm 277.2^{* *}$ & $37.7 \pm 7.2^{* * \wedge}$ & $2.0 \pm 0.4^{*}$ \\
NAC & 12 & $617.9 \pm 344.5^{* *}$ & $30.3 \pm 15.8^{*}$ & $1.7 \pm 0.9^{* *}$ \\
\hline
\end{tabular}

${ }^{\# \#} P<0.01$ versus normal group, ${ }^{* *} P<0.01$ versus model group, ${ }^{\wedge \wedge} P<0.01$ versus NAC group. Two rats in model group died in 6 weeks of modeling.
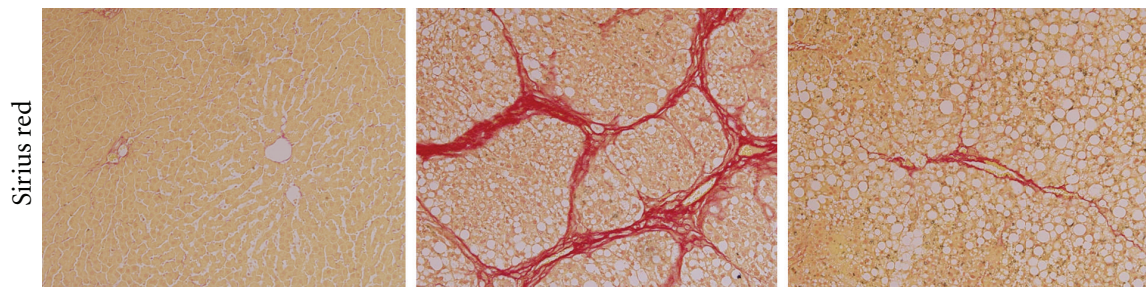

(a)

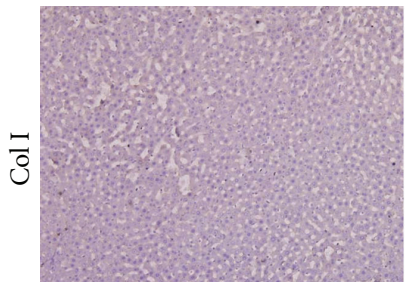

Normal

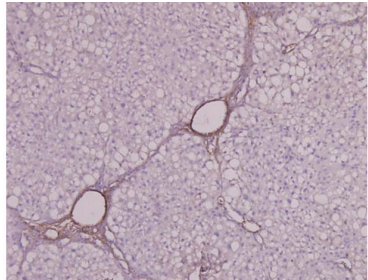

Model

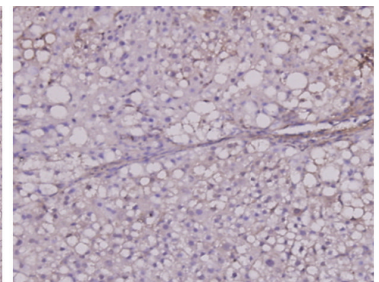

DBT
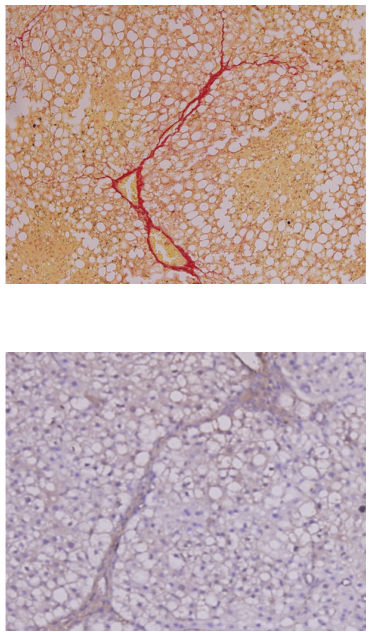

NAC

(b)

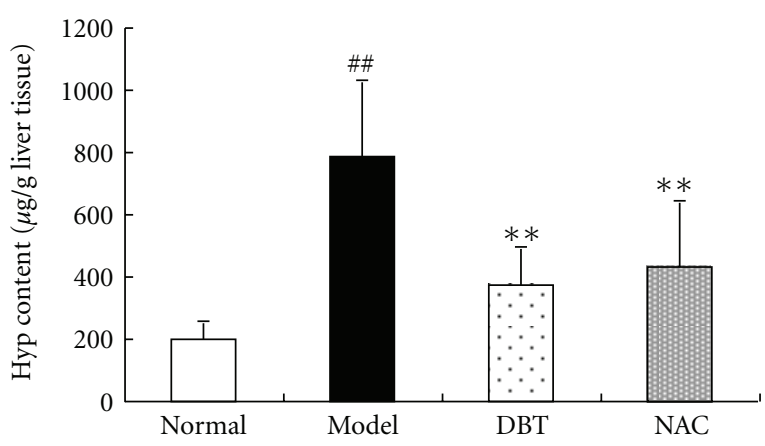

(c)

FIGURE 1: Effects of DBT and NAC on liver fibrosis induced by $\mathrm{CCl}_{4}$. (a) Sirius red staining of collagen deposition in liver fibrosis. $\mathrm{CCl}_{4}$ induced an increase in liver collagen. DBT and NAC decreased the collagen deposition in the fibrotic liver tissue. (b) Immunohistochemical staining of type I collagen protein expression in liver tissue (DAB). The model group had much stronger and more extensive positive staining among fibrotic septa compared with the normal group. DBT and NAC significantly decreased the amount of positive staining. (c) Liver Hyp content was determined using Jamall's method. The Hyp content was increased significantly in the model group compared with the normal group. DBT and NAC treatment significantly decreased liver Hyp content. ${ }^{\#} P<0.01$ versus normal group, ${ }^{* *} P<0.01$ versus model group.

significantly decreased this expression (Table 4). This was confirmed with HIF-1 $\alpha$ immunostaining (Figure 4 ). In the livers of normal animals, HIF- $1 \alpha$ immunolabeling was rarely detected. In the fibrotic livers, HIF- $1 \alpha$ immunolabeling was highly expressed, especially in zone III of the acinus. DBT and NAC decreased HIF- $1 \alpha$ expression in the fibrotic livers $(P<0.05)$. Consistent with the immunohistochemistry findings, western blot analysis showed that HIF- $1 \alpha$ expression was significantly increased in the fibrotic livers $(P<0.01$, versusnormal group). DBT and NAC decreased HIF- $1 \alpha$ expression $(P<0.01)$, with a significant difference between the two treatment groups $(P<0.01)$.

3.5. Effects of DBT and NAC on Hepatic Oxidative Injury. $\mathrm{CCl}_{4}$ intoxication significantly increased hepatic contents of MDA and 8-OH-dG, and decreased hepatic SOD activity (Table 5) $(P<0.01$, versus normal group). DBT and NAC 


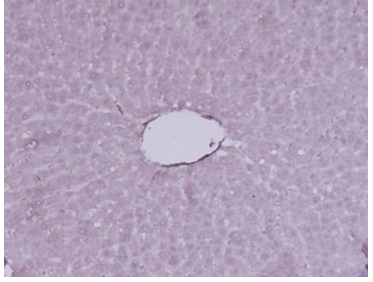

Normal

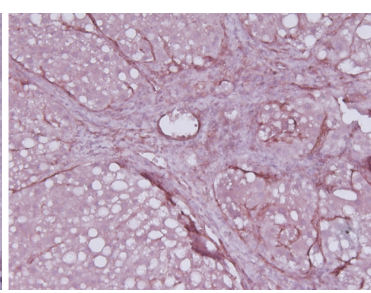

Model

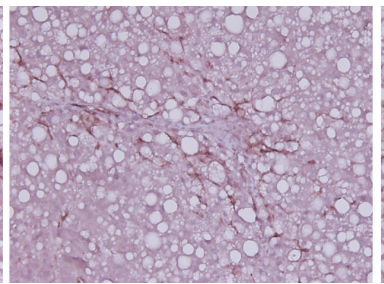

DBT

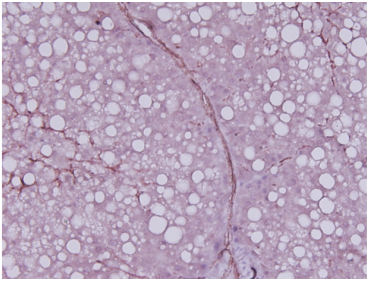

NAC

(a)

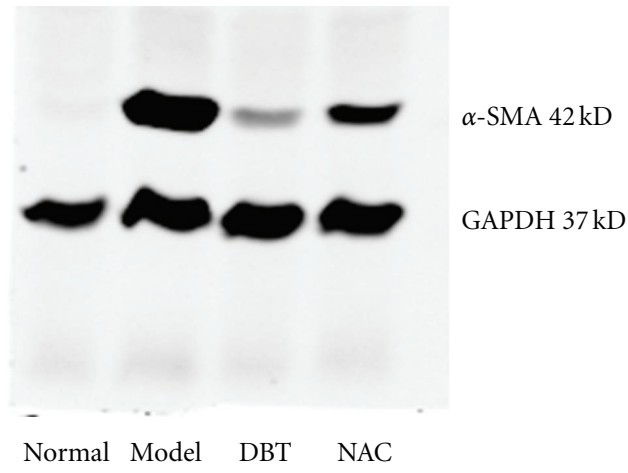

(b)

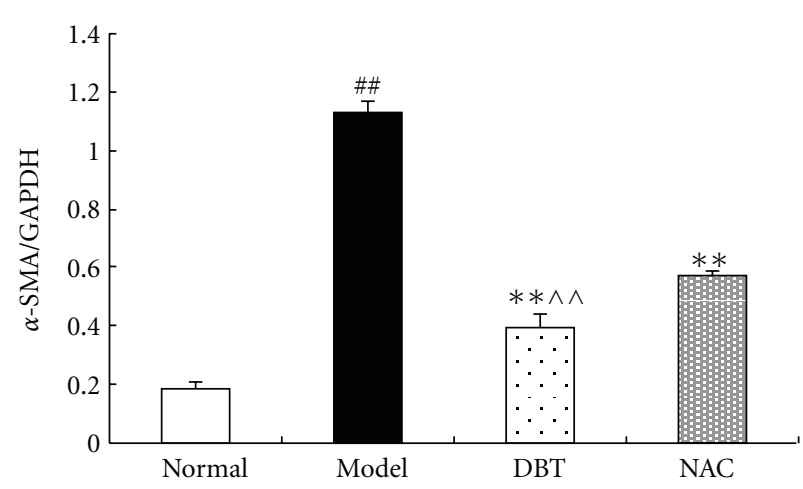

(c)

FIGURE 2: Effect of DBT and NAC on $\alpha$-SMA protein expression in $\mathrm{CCl}_{4}$-induced fibrotic liver tissue in rats. (a) Immunohistochemical staining, $\mathrm{DAB} \times 200$. Normal liver tissue had little positive staining. Tissue from the model group had much stronger and more extensive positive staining among fibrotic septa and in the sinusoidal area. DBT and NAC significantly decreased the amount of positive staining. (b) A representative western blot. Consistent with the immunohistochemistry findings, the semi-quantitative value of the $\alpha$-SMA western blot was significantly increased in fibrotic livers. Compared to the model control group, DBT significantly decreased $\alpha$-SMA expression, and the effect of DBT was more pronounced than that of NAC. (c) A histogram plot showing the densitometric analysis corresponding to the mean \pm SD of three independent experiments. ${ }^{\#} P<0.01$ versus normal group, ${ }^{* *} P<0.01$ versus model group, ${ }^{\wedge} P<0.01$ versus NAC group.

reduced hepatic MDA and 8-OH-dG contents, increased the SOD activity $(P<0.05)$. In addition, DBT has better effect than NAC on increasing SOD activity in fibrotic liver.

\subsection{Effects of DBT and NAC on Expression of VEGF, Ang1} and TGF- $\beta 1$ and Their Signaling Mediators. Western blot analysis (Figure 5) showed that the expressions of proangiogenic growth factors such as VEGF, TGF- $\beta 1$, and Ang1 elevated in fibrotic livers $(P<0.01$, versus normal group), and their respective receptors-VEGF-R2, TGF $\beta$ R$1 / 2$ and Tie 2 also increased. ERK is common down-stream signaling mediator for VEGF, TGF- $\beta 1$, and so forth, the result showed that phosphorylation of ERK-1/2 increased remarkably, although total ERK1 has no change. DBT, but not NAC, significantly decreased VEGF and VEGF-R2 protein expression $(P<0.01)$, and there was a significant difference in VEGF expression between DBT- and NACtreated groups. $(P<0.01)$. Both DBT and NAC downregulated TGF $\beta-\mathrm{R} 1 / 2$ and Tie2 expression and ERK-1/2 phosphorylation in fibrotic liver $(P<0.05)$, compared to the model control.

\section{Discussion}

The liver fibrosis, caused by many etiologies such as viruses, toxins, alcohol and cholestasis and so forth, is an essential pathological process in chronic liver diseases, and lead into cirrhosis which is end stage of chronic liver diseases. Therefore, it is very important to find an approach for curing or regressing liver fibrosis. Angiogenesis is the main process of new vessel formation, and accompanies liver fibrosis [2]. Recently a increasing body of evidences has shown that angiogenesis play a crucial role in liver fibrogenesis [14], and the inhibition of angiogenesis with multitargeted receptor tyrosine kinase inhibitors sunitinib or sorafenib could regress or reverse liver fibrosis in animals $[15,16]$. Angiogenesis, a hypoxia-driven and growth factor-dependent process, also plays a key role in the development of cirrhosis $[1,2,5,17-$ 20]. Since the conventional therapies are not desirable for curing liver fibrosis, the manipulation of angiogenesis could be a promising approach for treatment of liver fibrosis.

According to traditional Chinese medicine (TCM) theory, liver fibrosis is caused by a dual deficiency of Qi-yin and blood stasis [21]. DBT has good function of nourishing Qi (energy flow) and Xue (blood), as well as resolving Yuxue (blood stasis), and has been used traditionally to treat menopausal disorders [6]. In our previous study, we found that DBT could ameliorate $\mathrm{CCl}_{4}$-induced liver fibrosis in rats [11]. In this study, we found that in normal livers, vWF and CD31, two markers of angiogenesis, are expressed few and limited to the large vessels of the periportal region and could not be found along sinusoids. However, their 

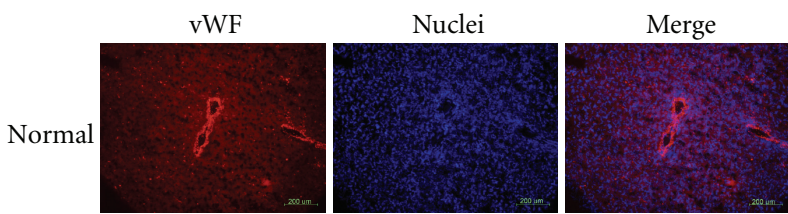

Model
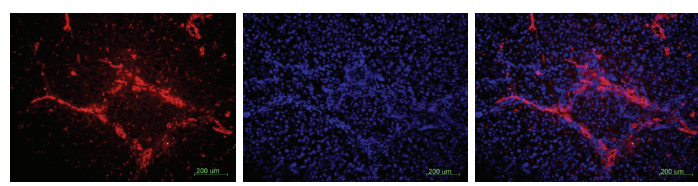

DBT
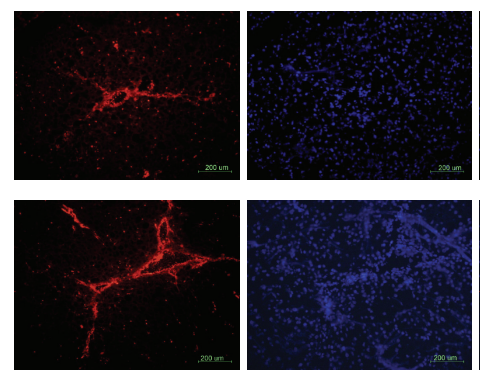

(a)

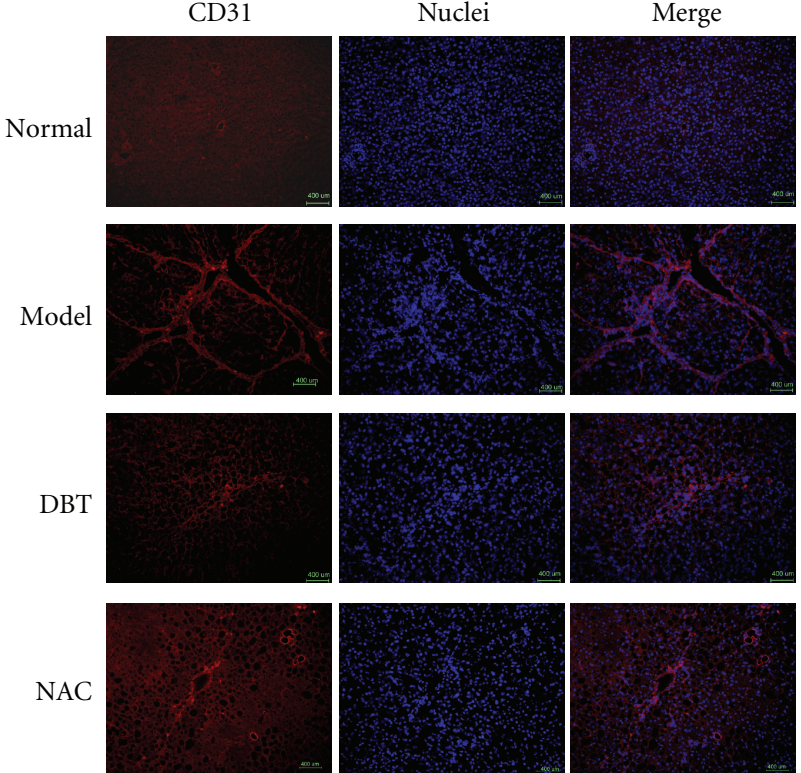

(b)

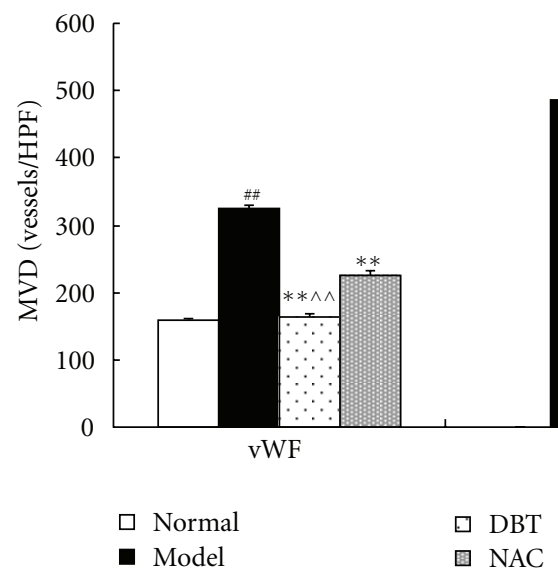

(c)

Figure 3: Effect of DBT and NAC on vWF and CD31 expression in $\mathrm{CCl}_{4}$-induced fibrotic liver tissue in rats, (a, b) Microvessel density in different groups. Immunofluorescence for vWF and CD31 was performed to analyze microvessel growth. In normal livers, the expression of vWF was limited to large vessels located in the periportal zone with no expression along the sinusoids, and no CD31 expression was observed. In $\mathrm{CCl}_{4}$-treated livers, increased vWF/CD31-positive microvessels were seen primarily in fibrotic areas. DBT- and NAC-treated livers showed reduced amounts of vWF/CD31-positive microvessels, which were also concentrated in fibrotic areas. A significant difference in vWF expression was seen between DBT- and NAC-treated groups. (c) A bar graph representation of microvessel density reported as the mean number of labeled vessel sections in 5 successive high-magnification fields $(\times 400)$. The results are expressed as mean \pm SD for three separate experiments. ${ }^{\#} P<0.01$ versus normal group, ${ }^{* *} P<0.01$ versus model group, ${ }^{\wedge} P<0.01$ versus NAC group.

expression increased remarkably in fibrous septa and along sinusoids in fibrotic livers, which means that rich neovessels formed in fibrotic livers. While DBT and NAC treatment could decrease the expression of vWF and CD31 proteins, indicating that DBT and NAC can inhibit liver angiogenesis, which may be one of the action mechanisms of DBT and NAC antifibrotic property. It is reported recently that the thiol antioxidant NAC had effect against liver fibrosis [22] and decreased tumor angiogenesis and tumorigenesis [23]; our current study confirmed NAC's effect on liver fibrosis and find its new action on fibrotic liver angiogenesis.

Angiogenesis is a dynamic, hypoxia-stimulated and growth factor-dependent process. A recent document has identified that there are number of common cellular and molecular mechanisms between angiogenesis and liver fibrosis, with a specific emphasis on the crucial role of hypoxic conditions, angiogenic factors and HSC activation. The hypoxia play a central role in angiogenesis through 


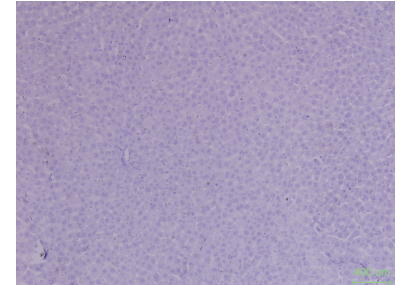

Normal

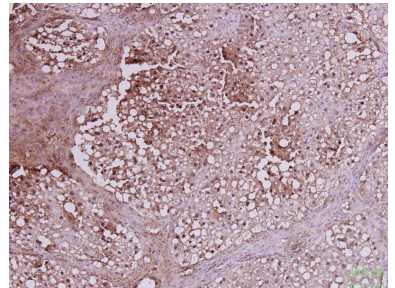

Model

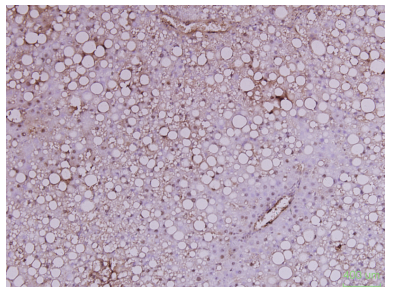

DBT

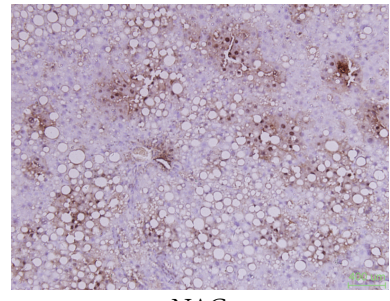

NAC

(a)

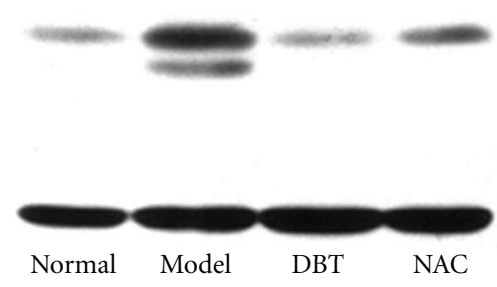

(b)

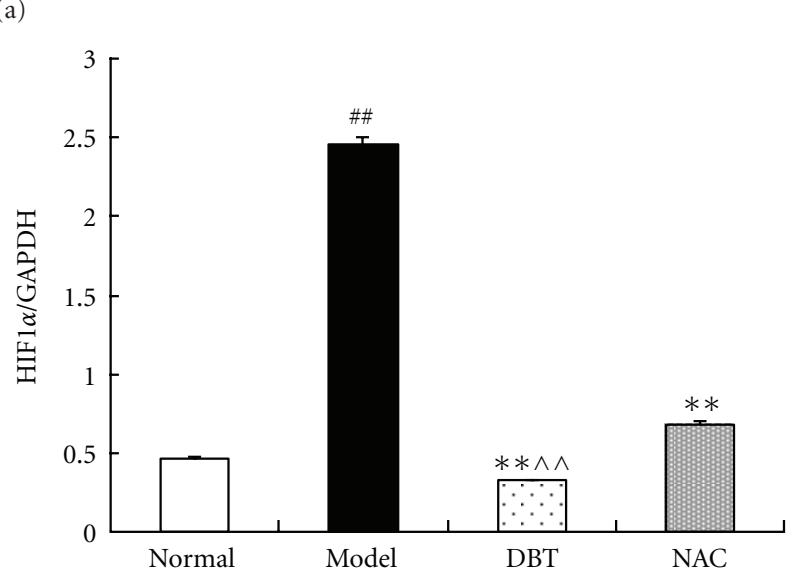

(c)

FIGURE 4: Effect of DBT and NAC on HIF- $1 \alpha$ protein expression in $\mathrm{CCl}_{4}$-induced fibrotic liver tissue in rats. (a) Immunohistochemistry $(\mathrm{DAB} \times 200)$. In normal livers, HIF- $1 \alpha$ immunolabeling was rarely detected. In fibrotic livers, HIF- $1 \alpha$ immunolabeling was highly expressed, especially in zone III of the acinus. DBT and NAC decreased HIF- $1 \alpha$ expression in the fibrotic livers. (b) A representative western blot. Consistent with the immunohistochemistry findings, the semiquantitative value of the HIF-1 $\alpha$ western blot was significantly increased in fibrotic livers. Compared to the model rats, DBT and NAC significantly decreased the expression of HIF- $1 \alpha$, with DBT being more effective than NAC. (c) A histogram showing HIF- $1 \alpha$ protein semiquantified by densitometric analysis and expressed as the mean \pm SD for three separate experiments. ${ }^{\#} P<0.01$ versus normal group, ${ }^{* *} P<0.01$ versus model group, ${ }^{\wedge} P<0.01$ versus NAC group.

inducing HIF- $1 \alpha$ [24]. HIF- $1 \alpha$ is a heterodimeric DNA binding complex, it serve as a key regulator of the molecular hypoxia response and mediates a wide range of physiological and pathological processes. In the study, although we did not check hepatic hypoxia by assaying $\mathrm{pO}_{2}$ etc., $\mathrm{HIF}-1 \alpha$, a hypoxia-driven factor, was mainly expressed in perivenous region (hepatic zone III area) where $\mathrm{O}_{2}$ concentration is lowest in liver and susceptible to be damaged. And fibrotic liver had much higher levels of gene and protein expression of HIF- $1 \alpha$, while DBT and NAC decrease this pathological elevated HIF- $1 \alpha$ levels, in particular HIF- $1 \alpha$ expression in perivenous region, these suggested that DBT and NAC action against liver angiogenesis was associated with downregulation of HIF- $1 \alpha$, which at least partly own to improving hypoxia condition.

However, HIF-1 $\alpha$ upregulation could be hypoxiaindependent, as elicited by growth factors, oncogenes, and oxidative stress and injury and so forth. The oxidative stress could cause lipid peroxidative products such as MDA and 8-OH-dG, leading to liver injury and angiogenesis [25], which can be regulated by endogenous antioxidant enzymes such as SOD and thioredoxin [26]. Recent studies have shown that antioxidants such as NAC can inhibit tumor angiogenesis [27]. In the study, we found DBT and NAC both improve SOD activity but decrease contents of MDA and $8-\mathrm{OH}-\mathrm{dG}$ in fibrotic liver, indicating that DBT and NAC inhibition of HIF- $1 \alpha$ and angiogenesis is related to their effect on oxidative stress and injury. VEGF, TGF- $\beta 1$, and Ang1 are potent angiogenic and fibrogenic factors, which may induce angiogenesis directly through their signaling pathway or indirectly by inducing HIF- $1 \alpha$ which in turn promote its target genes including VEGF expression. VEGF, TGF- $\beta 1$ and Ang1 stimulate vascular development and stabilization through signaling mediators, including their receptors-VEGF-R1/2 and TGF $\beta$-R1/2, Tie 2 and mitogenactivated protein kinase (MAPK) cascade $[28,29]$. In the present study, DBT not only inhibited the expression of growth factors including VEGF, TGF- $\beta 1$, and Ang1, but also downregulated their receptors expression and ERK phosphorylation which is common cytoplasmic mediator, indicating that the inhibition of VEGF, TGF- $\beta 1$ and Ang1 and their signaling is another important mechanism for DBT action on HIF- $1 \alpha$, and against angiogenesis and liver fibrosis.

In addition, MMP-2/9 play potent role in initiation of angiogenesis and activation of HSC, while activated HSCs synthesizing Ang 1 and VEGF contribute to both fibrogenesis and neovascularization [20]. In a previous study, we showed that the protective effect of DBT was associated with the 


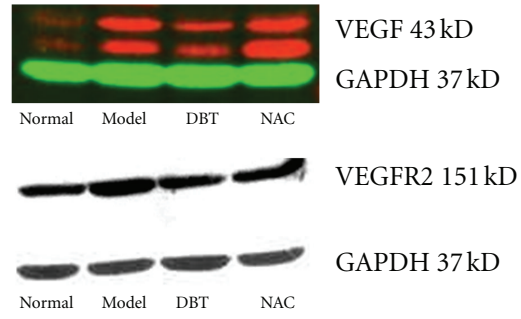

(a)



(c)

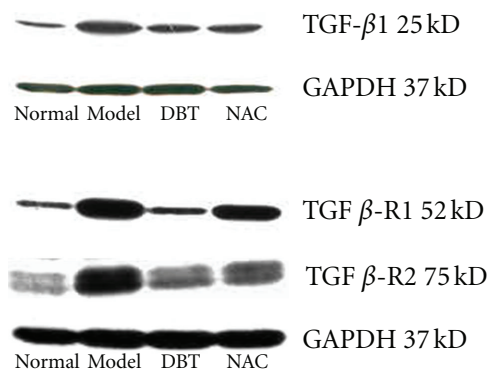

(e)

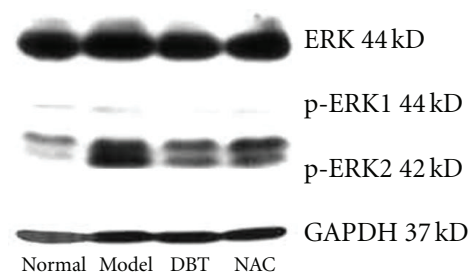

(g)

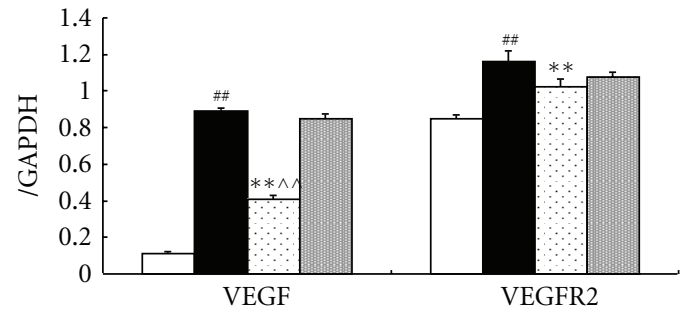

(b)

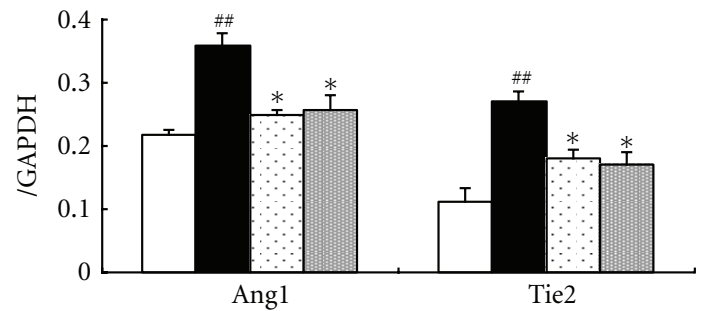

(d)

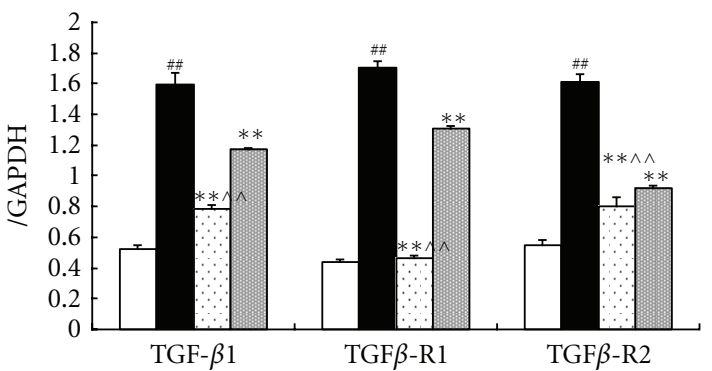

(f)

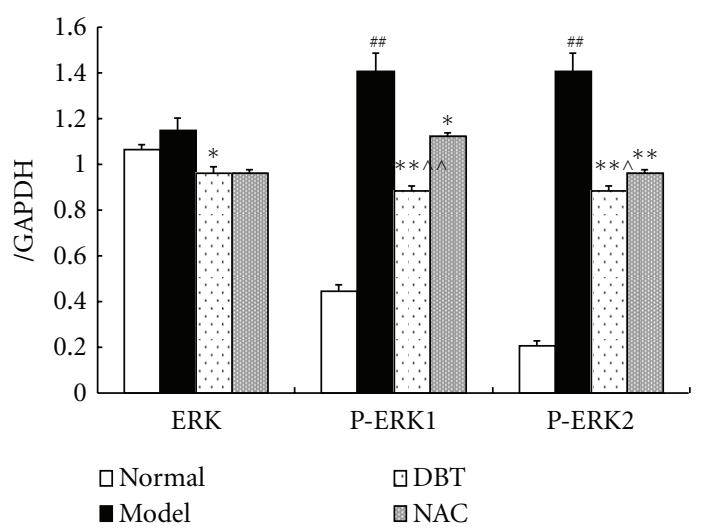

(h)

FIgure 5: Effect of DBT and NAC on VEGF, Angiopoietin 1 and TGF- $\beta 1$ signaling in $\mathrm{CCl}_{4}$-induced fibrotic liver tissue in rats. (a) The expression of VEGF and VEGFR2 protein was detected by western blot. Compared to the normal group, the expression of VEGF and VEGFR2 was significantly increased in fibrotic livers. DBT, but not NAC, significantly decreased VEGF and VEGFR2 expression, and there was a significant difference in VEGF expression between DBT- and NAC-treated groups. (c) The expression of the Angiopoietin 1 and Tie 2 protein was detected by western blot. Compared to the normal group, the expression of Ang1 and Tie 2 was increased in fibrotic livers. DBT and NAC decreased Ang1 and Tie 2 expression. (e) The expression of the TGF- $\beta 1 /$ TGF $\beta$-R protein was detected by western blot. Compared to the normal group, TGF $\beta 1 /$ TGF $\beta$-R protein expression was significantly increased in fibrotic livers. DBT and NAC significantly decreased the expression of TGF $\beta 1 /$ TGF $\beta$-R. (g) The expression of ERK and p-ERK protein was detected by western blot. Although there was no significant difference in ERK protein expression among the four groups, p-ERK protein expression was significantly increased in fibrotic livers. DBT and NAC significantly decreased p-ERK protein expression, and there was a significant difference between DBT- and NAC-treated groups. (b, $\mathrm{d}, \mathrm{f}, \mathrm{h}$ ) Histograms of VEGF/VEGFR2, Ang1/Tie 2, TGF $\beta 1 / T G F \beta$-R, and ERK/p-ERK expression. The proteins were semi-quantified by densitometric analysis and expressed as the mean \pm SD for three separate experiments. ${ }^{\# \#} P<0.01$ versus normal group, ${ }^{* *} P<0.01$ versus model group, ${ }^{\wedge \wedge} P<0.01$ versus NAC group. 
inhibition of MMP 2/9 activities in fibrotic livers [11]. And the current experiment reconfirmed that DBT and NAC inhibited HSC activation in vivo, which suggest that inhibition of MMP-2/9 and HSC activation is the third mechanism of DBT action mechanism against angiogenesis in fibrotic liver.

It is interesting to note that DBT can stimulate the production of erythropoietin, a specific hematopoietic growth factor, mediated by increasing the mRNA and protein expression of HIF- $1 \alpha$ as well as the activation of Raf/MEK/ERK signaling pathway in cultured cells [30]. While these data appear to contradict our findings, these data collectively illustrate the potential of DBT and other herbal formulations in modulating cellular pathophysiology to achieve the desirable clinical outcome.

In summary, we found that DBT inhibits angiogenesis in $\mathrm{CCl}_{4}$-induced liver fibrosis in rats in the current study, which is closely related to DBT anti-fibrotic property; and that DBT reduces the expression of HIF- $1 \alpha$, VEGF, TGF- $\beta 1$, and Ang1, decreases the receptors expression of VEGF-R2, TGF $\beta$-R1/2 and Tie2, downregulates ERK phosphorylation, and improves hepatic oxidative injury in fibrotic liver; these effects contribute to the overall action mechanisms of DBT against liver angiogenesis and fibrosis.

\section{Glossary}

$\begin{array}{ll}\text { DBT: } & \text { Danggui Buxue Tang } \\ \text { NAC: } & \text { N-Acetyl-L-cysteine } \\ \text { CCl } 4: & \text { Carbon tetrachloride } \\ \alpha \text {-SMA: } & \text { Alpha-smooth muscle actin } \\ \text { HIF- } 1 \alpha: & \text { Hypoxia inducible factor- } 1 \alpha \\ \text { vWF: } & \text { von Willebrand factor }\end{array}$

PECAM-1: Platelet/endothelial cell adhesion molecule-1, also referred to as CD31

VEGF: Vascular endothelial growth factor

VEGF-R2: Vascular endothelial growth factor receptor 2, also referred to as KDR

TGF- $\beta 1$ : Transforming growth factor- $\beta 1$

TGF $\beta$-R: Transforming growth factor- $\beta 1$ receptor

p-ERK: Phospho-extracellular signal-regulated kinase

BSA: Bovine serum albumin

ECM: Extracellular matrix

CLDs: $\quad$ Chronic liver diseases

DAPI: 2-(4-Amidinophenyl)-6-indolecarbamidine dihydrochloride

Hyp: $\quad$ Hydroxyproline

HSC: Hepatic stellate cell

MMPs: Metalloproteinases

SOD: $\quad$ Superoxide dismutase

MDA: Malondialdehyde

8-0H-dG: 8-hydroxy-deoxyguanosine

Ang1: Angiopoietin 1

Tie2: $\quad$ Tyrosine kinase with immunoglobulin G-like and endothelial growth factor-like domain 2.

\section{Acknowledgments}

This work was supported by the following grants: National Natural Science Foundation of China (no. 81173405 and no. 81102702), Program for Outstanding Medical Academic Leader of Shanghai Municipality (LJ10005), Leading Academic Discipline of Hepatology of State Administration of TCM China (no. 2010sh), E-Institute (E03008) and Innovative Research Team in Universities of Shanghai Municipal Education Commission. This work has also received funding from the European Union's Framework Programme 7 [FP7/2007-2013] under the Grant agreement no. 223154.

\section{References}

[1] M. Fernández, D. Semela, J. Bruix, I. Colle, M. Pinzani, and J. Bosch, "Angiogenesis in liver disease," Journal of Hepatology, vol. 50, no. 3, pp. 604-620, 2009.

[2] C. Corpechot, V. Barbu, D. Wendum et al., "Hypoxiainduced VEGF and collagen I expressions are associated with angiogenesis and fibrogenesis in experimental cirrhosis," Hepatology, vol. 35, no. 5, pp. 1010-1021, 2002.

[3] J. Medina, A. G. Arroyo, F. Sánchez-Madrid, and R. MorenoOtero, "Angiogenesis in chronic inflammatory liver disease," Hepatology, vol. 39, no. 5, pp. 1185-1195, 2004.

[4] D. Thabut, C. Routray, G. Lomberk et al., "Complementary vascular and matrix regulatory pathways underlie the beneficial mechanism of action of sorafenib in liver fibrosis," Hepatology, vol. 54, no. 2, pp. 573-585, 2011.

[5] O. Rosmorduc, "Antiangiogenic therapies in portal hypertension: a breakthrough in hepatology," Gastroenterologie Clinique et Biologique, vol. 34, no. 8-9, pp. 446-449, 2010.

[6] Q. Gao, J. Li, J. K. H. Cheung et al., "Verification of the formulation and efficacy of Danggui Buxue Tang (a decoction of Radix Astragali and Radix Angelicae Sinensis): an exemplifying systematic approach to revealing the complexity of Chinese herbal medicine formulae," Chinese Medicine, vol. 2, article 12, 2007.

[7] H. Wang, J. Li, L. Yu, Y. Zhao, and W. Ding, "Antifibrotic effect of the Chinese herbs, Astragalus mongholicus and Angelica sinensis, in a rat model of chronic puromycin aminonucleoside nephrosis," Life Sciences, vol. 74, no. 13, pp. 1645-1658, 2004.

[8] H. Ma, B. E. Wang, Y. Y. Chen et al., "The therapeutic effect of Astragalus mernbranaceus on liver fibrosis induced by immunologic injury in rats," Chinese Journal of Integrated Traditional and Western Medicine on Liver Diseases, vol. 7, no. 1, pp. 32-35, 1997.

[9] Y. Y. Jiang, S. H. Cao, and Z. K. Sun, "Study to effect of Angelica sinensis on the development of pulmonary fibrosis," Journal of Chinese Microcirculation, vol. 10, no. 5, pp. 326-328, 2006.

[10] Y. Y. Tao, Y. Chen, G. F. Chen et al., "Anti-hepatic fibrosis effect of, "Danggui Buxue decoction" with different proportions of Radix Astraga and Angelica sinensis in rats," Acta Universitatis Traditionis Medicalis Sinensis Pharmacologiaeque Shanghai, vol. 22, no. 1, pp. 40-44, 2008.

[11] Y. Chen, Q. Chen, J. Lu, F. H. Li, Y. Y. Tao, and C. H. Liu, "Effects of Danggui Buxue decoction on lipid peroxidation and MMP-2/9 activities of fibrotic liver in rats," Chinese Journal of Integrative Medicine, vol. 15, no. 6, pp. 435-441, 2009.

[12] B. M. Sun, H. P. Xuan, F. H. Li et al., "Effects of Cordyceps mycelium extract on steatohepatitis and liver fibrosis in rats," 
Chinese Journal of New Drugs and Clinical Remedies, vol. 27, no. 1, pp. 6-11, 2008.

[13] I. S. Jamall, V. N. Finelli, and S. S. Que Hee, "A simple method to determine nanogram levels of 4-hydroxyproline in biological tissues," Analytical Biochemistry, vol. 112, no. 1, pp. 70-75, 1981.

[14] J. S. Lee, D. Semela, J. Iredale, and V. H. Shah, "Sinusoidal remodeling and angiogenesis: a new function for the liverspecific pericyte?" Hepatology, vol. 45, no. 3, pp. 817-825, 2007.

[15] S. Tugues, G. Fernandez-Varo, J. Muñoz-Luque et al., "Antiangiogenic treatment with sunitinib ameliorates inflammatory infiltrate, fibrosis, and portal pressure in cirrhotic rats," Hepatology, vol. 46, no. 6, pp. 1919-1926, 2007.

[16] M. Mejias, E. Garci-Pras, C. Tiani, R. Miquel, J. Bosch, and M. Fernandez, "Beneficial effects of sorafenib on splanchnic, intrahepatic, and portocollateral circulations in portal hypertensive and cirrhotic rats," Hepatology, vol. 49, no. 4, pp. 12451256, 2009.

[17] C. W. Pugh and P. J. Ratcliffe, "Regulation of angiogenesis by hypoxia: role of the HIF system," Nature Medicine, vol. 9, no. 6, pp. 677-684, 2003.

[18] P. Carmeliet, "Angiogenesis in health and disease," Nature Medicine, vol. 9, no. 6, pp. 653-660, 2003.

[19] K. Taura, S. De Minicis, E. Seki et al., "Hepatic stellate cells secrete angiopoietin 1 that induces angiogenesis in liver fibrosis," Gastroenterology, vol. 135, no. 5, pp. 1729-1738, 2008.

[20] E. Novo, S. Cannito, E. Zamara et al., "Proangiogenic cytokines as hypoxia-dependent factors stimulating migration of human hepatic stellate cells," American Journal of Pathology, vol. 170, no. 6, pp. 1942-1953, 2007.

[21] Liver Disease Committee, Chinese Association of Integrative Medicine, "Guidelines for the diagnosis and treatment of liver fibrosis in integrative medicine practice," Zhonghua Gan Zang Bing Za Zhi, vol. 14, no. 11, pp. 866-870, 2006.

[22] G. Tahan, O. Tarcin, V. Tahan et al., "The effects of Nacetylcysteine on bile duct ligation-induced liver fibrosis in rats," Digestive Diseases and Sciences, vol. 52, no. 12, pp. 33483354, 2007.

[23] A. Agarwal, U. Muñoz-Nájar, U. Klueh, S. C. Shih, and K. P. Claffey, "N-acetyl-cysteine promotes angiostatin production and vascular collapse in an orthotopic model of breast cancer," American Journal of Pathology, vol. 164, no. 5, pp. 1683-1696, 2004.

[24] C. Paternostro, E. David, E. Novo, and M. Parola, "Hypoxia, angiogenesis and liver fibrogenesis in the progression of chronic liver diseases," World Journal of Gastroenterology, vol. 16, no. 3, pp. 281-288, 2010.

[25] M. Ushio-Fukai and R. W. Alexander, "Reactive oxygen species as mediators of angiogenesis signaling. Role of $\mathrm{NAD}(\mathrm{P}) \mathrm{H}$ oxidase," Molecular and Cellular Biochemistry, vol. 264, no. 12, pp. 85-97, 2004.

[26] J. Grzenkowicz-Wydra, J. Cisowski, J. Nakonieczna et al., "Gene transfer of CuZn superoxide dismutase enhances the synthesis of vascular endothelial growth factor," Molecular and Cellular Biochemistry, vol. 264, no. 1-2, pp. 169-181, 2004.

[27] T. Cai, G. Fassina, M. Morini et al., "N-acetylcysteine inhibits endothelial cell invasion and angiogenesis," Laboratory Investigation, vol. 79, no. 9, pp. 1151-1159, 1999.

[28] H. Yoshiji, S. Kuriyama, J. Yoshii et al., "Vascular endothelial growth factor and receptor interaction is a prerequisite for murine hepatic fibrogenesis," Gut, vol. 52, no. 9, pp. 13471354, 2003.

[29] M. Hennenberg, J. Trebicka, C. Stark, A. Z. Kohistani, J. Heller, and T. Sauerbruch, "Sorafenib targets dysregulated Rho kinase expression and portal hypertension in rats with secondary biliary cirrhosis," British Journal of Pharmacology, vol. 157, no. 2, pp. 258-270, 2009.

[30] K. Y. Z. Zheng, R. C. Y. Choi, H. Q. H. Xie et al., "The expression of erythropoietin triggered by Danggui Buxue Tang, a Chinese herbal decoction prepared from Radix Astragali and Radix Angelicae Sinensis, is mediated by the hypoxia-inducible factor in cultured HEK293T cells," Journal of Ethnopharmacology, vol. 132, no. 1, pp. 259-267, 2010. 


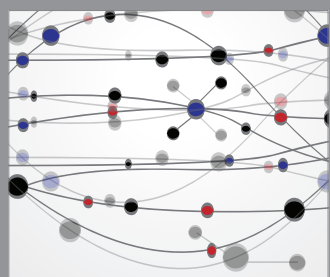

The Scientific World Journal
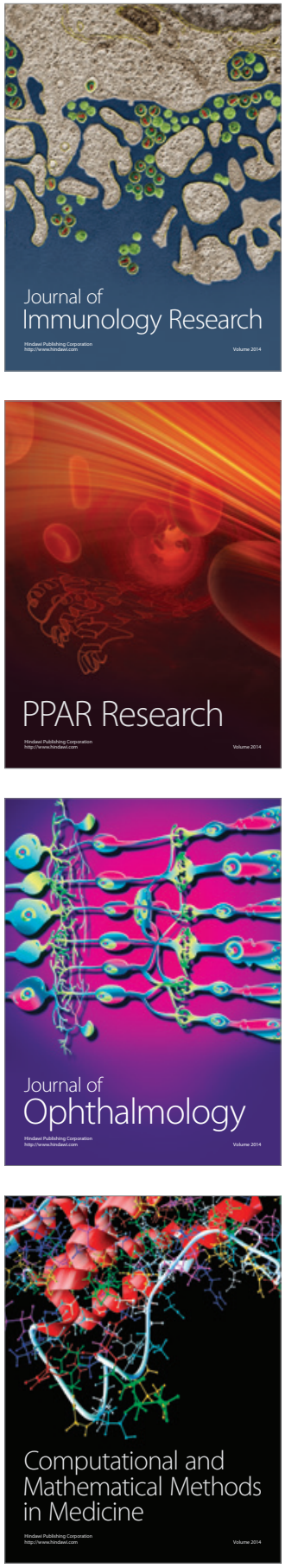

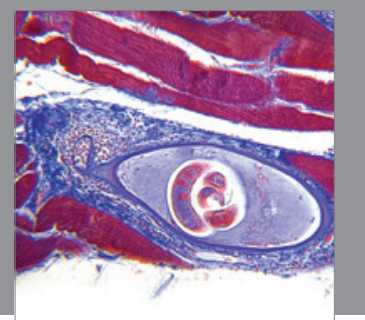

Gastroenterology

Research and Practice
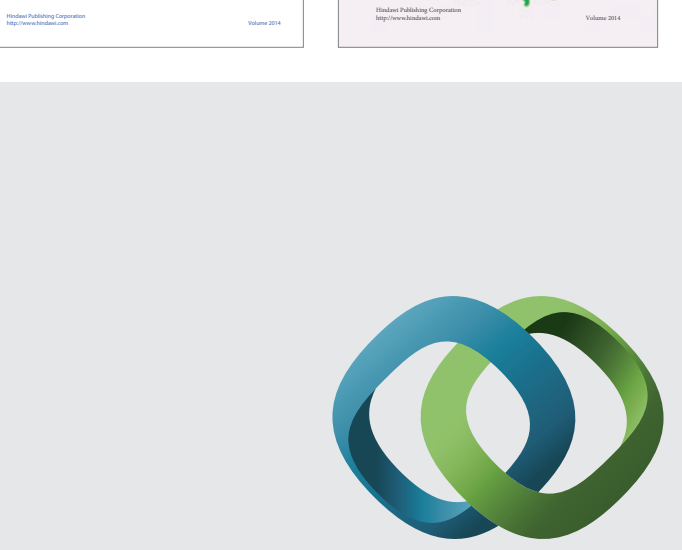

\section{Hindawi}

Submit your manuscripts at

http://www.hindawi.com
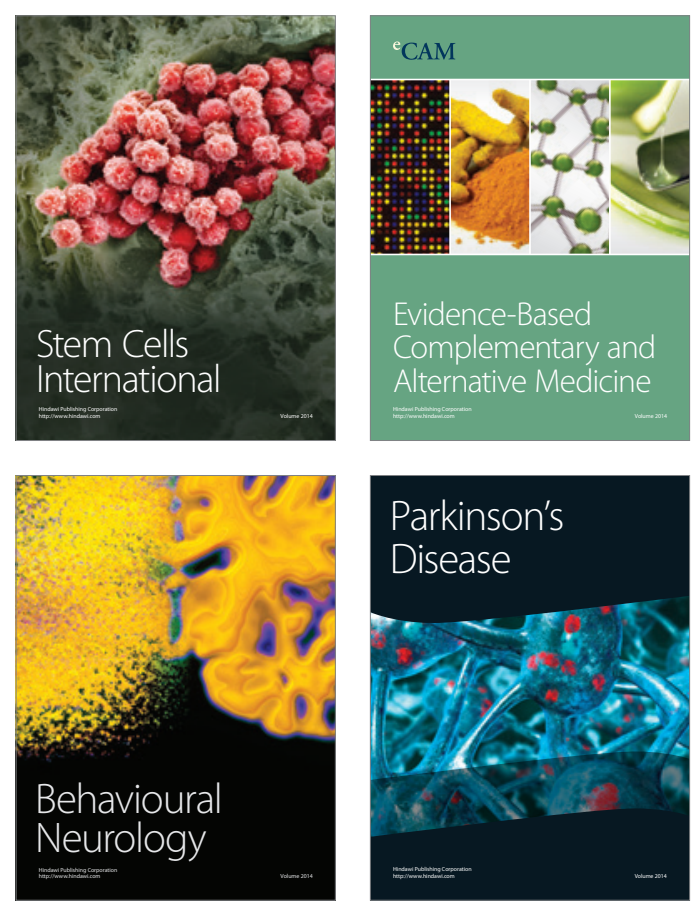



Journal of
Diabetes Research

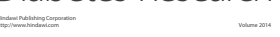

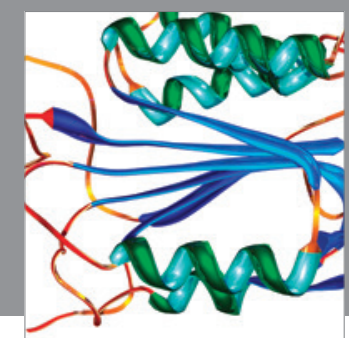

Disease Markers
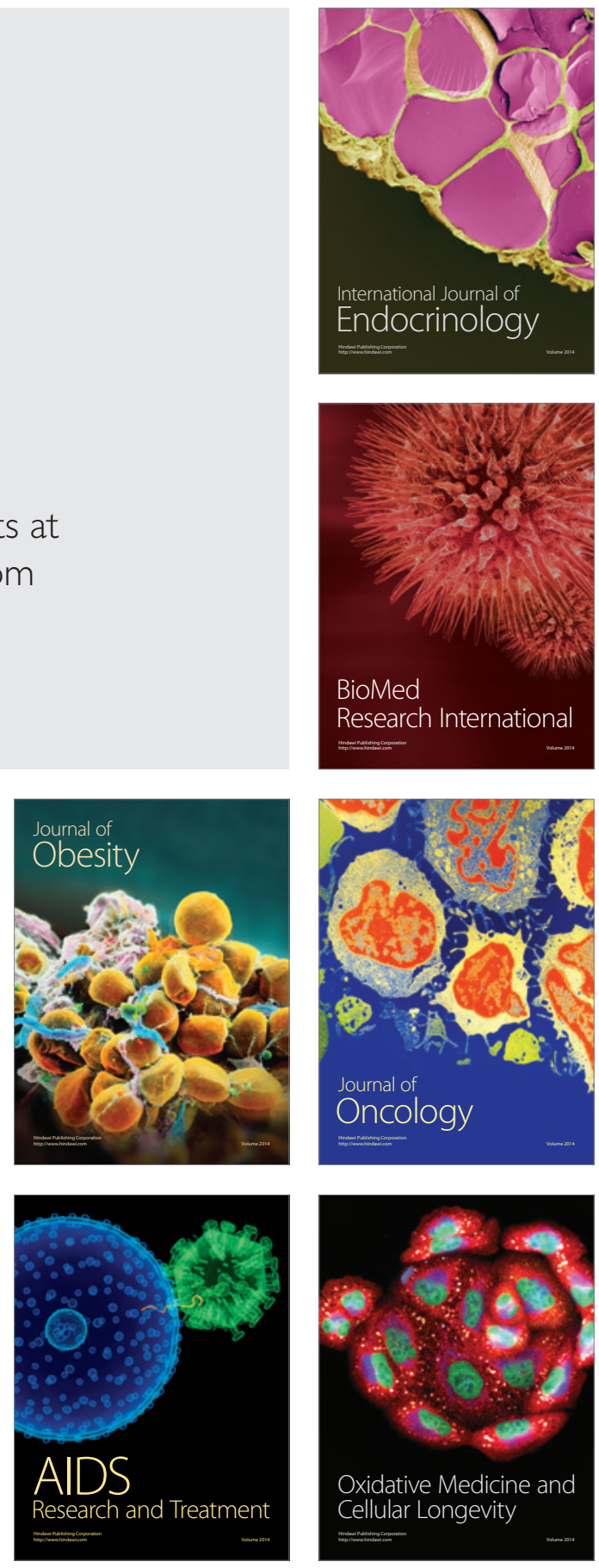